\title{
In-Plane Shear Performance of Wood-Framed Drywall Sheathing Wall Systems under Cyclic Racking Loading
}

\author{
Ali M. Memari1,2, Ryan L. Solnosky ${ }^{1}$ \\ ${ }^{1}$ Department of Architectural Engineering, The Pennsylvania State University, University Park, USA \\ ${ }^{2}$ Department of Civil and Environmental Engineering, The Pennsylvania State University, State College, USA \\ Email: memari@engr.psu.edu, rls5008@engr.psu.edu
}

Received 5 January 2014; revised 5 February 2014; accepted 12 February 2014

Copyright (C) 2014 by authors and Scientific Research Publishing Inc.

This work is licensed under the Creative Commons Attribution International License (CC BY). http://creativecommons.org/licenses/by/4.0/

(c) (i) Open Access

\section{Abstract}

A pilot study was conducted at Penn State University to determine whether the type of drywall joint compound would influence the shear strength of wood-frame stud walls sheathed with Gypsum Wall Board (GWB or drywall). In this study, five $2438 \mathrm{~mm}$ by $2438 \mathrm{~mm}$ specimens were tested under in-plane cyclic racking loading following the CUREE loading protocol for light-frame wall systems. Three specimens were finished using non-cement based joint compound while the other two used cement based joint compound. Based on the experimental testing of the specimens, the results show that the use of cement based joint compound on drywall joints produces higher shear capacity for the wall system as compared to similar specimens finished with conventional noncement based joint compound. The result of the study is particularly important for high seismic regions where interior stud walls in residential construction effectively take part in seismic resistance even though wood shear walls are normally used on exterior walls.

\section{Keywords}

Frames; Wood Structures; Studs; Shear Walls; Gypsum; Lateral Loads; Residential

\section{Introduction}

Past earthquakes, such as the Loma Prieta Earthquake (1989) for example, have demonstrated the vulnerability of light-frame construction in residential and commercial buildings. In light-frame construction, wood stud walls with drywall on both sides are commonly used in residential construction as interior walls/partitions. As such, they are considered "nonstructural" if they are not designed to carry no lateral load. The cost of repair to non- 
structural building components after an earthquake can be extensive and was estimated that about $50 \%$ of the total $\$ 18.5$ billion in damages to buildings during the Northridge Earthquake (1994) was in this classification [1]. Following the Northridge Earthquake, extensive studies have been undertaken to develop a better understanding of wood-frame construction. Although the contribution of such interior walls is usually not considered in design, nonetheless they do participate in lateral load resistance, as evidenced by damage to interior drywall in past earthquakes [2] [3].

If used as exterior shear walls (to resist wind and seismic loads), they are normally sheathed with plywood or oriented strand board (OSB) on the exterior and drywall on the interior. In either application, drywall joint compound is used with joint tape (paper or mesh) to cover the drywall joints. Although partitions and interior lightframe walls without plywood or OSB are not generally considered to be shear walls, the effective in-plane shear capacity of these walls can help the building perform better under wind and earthquake induced lateral loads as they can provide a source of reserve capacity. A detailed literature search has revealed limited studies are available when looking at interior wood shears walls with gypsum wall board (GWB) sheathing and even fewer are available for reinforced joints between sheathing panels. More on drywall sheathing wall systems are discussed in the next sections. Of the research conducted to date, many studies on residential walls have been conducted looking at steel and wood studs, different sheathing (e.g. drywall, OSB, plywood), connection and attachment mechanisms, and testing protocols. These studies provided insight into the benefits of drywall based shear walls used in residential construction. Additionally, through the literature review, prior work has indicated the advantages and disadvantages of each. One area was deemed worthy for future testing based on their results, joint compounds and joint finishes. More information into the prior is discussed in the next section.

To expand upon existing knowledge, this study looked at ways to reinforce drywall joints to provide additional shear strength to the system. In particular, a joint compound with cement in its mix could have a larger contribution compared to conventional joint compounds without any cement in their mixes. CTS Cement Manufacturing Company was interested to test this hypothesis through a pilot study. For this purpose, it was decided to test wood-frame wall specimens to compare the difference in shear capacity of specimens finished with Rapid Set OnePass joint compound (cement based) and those finished with conventional joint compound available in local hardware stores. The research undertaken in this study has addressed only the interior walls, meaning stud walls sheathed with drywall on both sides under cyclic loading.

Presented in this paper, the research results will help better document the in-plane shear performance of wood-stud interior walls with cement based joint compounds. These results may help acknowledge that interior walls can be considered to provide some additional overstrength capacity to the lateral force resisting systems such as shear walls and diaphragms.

\section{Literature Background}

Many studies have been conducted looking at residential construction related to shear walls either being wood framed or through steel studs. Materials acting as sheathing are equally varied. For wood based sheathing, Serrette et al. [4] compared the effect of various sheathing (including OSB and plywood) on wall behavior specifically looking at shear. Chen et al. [5] tested steel stud shear walls sheathed with wood structural panels. Their study looked at effect of screw spacing around the perimeter, type of wood structural sheathing, aspect ratio, and loading protocol type. Karacabeyli and Ceccotti [6] was one of the first to mix OSB and GWB on the same specimen. Uang and Gatto [7] and Hart et al. [8] looked into external wood shear walls with stucco finishes for the sheathing contribution. Uang and Gatto [7] further looked into mixing OSB and stucco and OSB and GWB in combinations. The results from these studies imply that having OSB and adding GWB or stucco on top will increase the shear capacity by up to $25 \%$. Hart et al. [9] looked into the performance of wood shear walls with GWB that had openings. Their study also started to look develop parameters to be used in performance-based design applications.

Studies by Wolfe [10], Zacher and Gray [16], Skaggs and Rose [11], McMullin and Merrick [12], Arnold et al. [13], and Lee et al. [14] to name a few have shown that shear walls of various configurations of GWB sheathed with one or two sides has shown enhanced performance in one or more areas (e.g. ductility, stiffness, strength) depending on the configuration(s). Van de Lindt [15] also looked at the affects the assemblies, particularly on the corners where two walls meet. 
Notable results from these studies include Wolfe's [10] study where the capacity of wood frame shear walls with structural wood panels on the exterior side and GWB on the interior side was evaluated. One conclusion of the study was that $4 \mathrm{ft} \times 8 \mathrm{ft}$ sheathing panels oriented horizontally will result in larger lateral load capacity of the wall compared with vertical orientation of the sheathing panels. Another conclusion was that GWB can provide additional lateral load capacity to shear walls. Serrette et al. [4] reported that GWB did not contribute significantly to the strength of the shear wall when OSB or plywood sheathing is used on the other side. Zacher and Gray [16] concluded that under cyclic loading conditions, GWB has little contribution to energy dissipation because of the crushing of the plaster in the GWB as the connectors press against the holes during racking movement. Karacabeyli and Ceccotti [6] concluded that using GWB on one side of shear walls increases the lateral load capacity, but not necessarily the ductility. Skaggs and Rose [11] concluded that GWB enhances the wall stiffness but does not increase lateral load capacity under racking movement. Between these studies and others, their results indicate a better understanding of such GWB based shear walls on the following issues:

- Contribution of GWB to overall shear capacity of the wall;

- Effect of various types of sheathing materials;

- Effect of connector spacing;

- Effect of aspect ratio;

- Effect of hold-down;

- Effect of monotonic loading vs. cyclic loading;

- Modes of failure.

Expanding upon the modes of failure observed in GWB applications, common failures can include: drywall cracking and breakage, drywall screw bending, and drywall screw head pull-out (separation from drywall but still attached to studs). These failure modes will be examined within this study.

Similar testing to wood stud GWB sheathed walls have been conducted with metal studs (steel stud shear walls) with GWB sheathing. Serrette el al. [4], NAHB Research Center [17], SEAOC [18], Bersofsky [19] and Chen et al. [5] have conducted prominent studies. NAHB Research Center [17] conducted tests with long steel stud shear walls with openings with OSB on the exterior side and GWB on the interior side. Observed in these tests where more common screw pull out through the drywall and weak-axis bending of studs. The SEAOC study [18] identified that under a cyclic loading protocol, walls with 2 in. screw spacing around the perimeter gave superior strength and stiffness characteristics compared to 6 in. spacing. In summary, these studies have looked at similar issues and behavior mechanisms as those studied on the wood shear walls previously listed.

In comparing the performances between wood and steel stud, Memari et al. [20] did such a study but also looked at the effect of finishing GWB panel joints (horizontal joints between drywall panels) with tape and joint compound. They concluded that the use of drywall joint compound can enhance the shear strength of light-frame walls. In fact, the finished wood-stud wall strength was 55\% higher compared to unfinished surface specimens and the steel-stud specimens showed about a $45 \%$ increase in strength over specimens without surface finish. The study presented herein will look to expand the study by Memari et al. [20] by looking more closely at wood shear walls with different joint finishes.

Prior to widespread use of cyclic loading, many wall tests were carried out using static monotonic loading. These monotonic testing procedures have long been standardized as ASTM E72 [21] and ASTM E564 [22]. Both methods of loading have been used to test wood-frame shear walls. One of the basic differences between the two standards is the mechanism of hold-down. ASTM E72 prescribes the use of tie-rods as the hold-down mechanism, while ASTM E564 uses devices or connectors that attach the frame bottom to the supporting base. The rationale for using tie-rods is to eliminate uplift in order to evaluate the shear capacity of the sheathing material for any given nail or screw spacing. ASTM E72's usage of tie-rods is clear and unique while ASTM E564 is non-specific may lead to the use of different hold-down devices.

While monotonic loading has its place, it is known that capacity degrades under back and forth movements such as earthquake loading. Based on this knowledge, cyclic loading protocols have been evolving to create a more realistic seismic loading condition for laboratory testing of light-frame structures. The loading rate is small enough to consider these protocols as "static" or "quasi-static", while having complete reversal of load in a cyclic manner. Several cyclic loading protocols have been suggested over the years including Sequential Phased Displacement Protocol (SEAOSC-SPD) [18], ASTM E2126 "Standard Test Methods for Cyclic (Reversed) Load Test for Shear Resistance of Walls for Buildings" [23], and Consortium of Universities for Research in Earthquake Engineering (CUREE) [24]. 
Several methods have common features such as increasing amplitudes of reversed cyclic loading up to a certain maximum load or displacement level, constant amplitude cycles (or stabilization cycles) at certain amplitude levels, and perhaps some amplitude decay (or degradation cycles). The various protocols differ in several aspects including the number of cycles of increasing amplitudes to reach a certain amplitude for constant amplitude interval (if any), number of cycles during the constant amplitude interval, number of cycles for the amplitude decay interval, target maximum amplitude, and loading rate. In general, these protocols rely on a target displacement, which is defined as the yield displacement. However, wood-frame shear walls do not have a well-defined yield point. Another drawback of some of these protocols has been that the number of cycles significantly exceeds what is usually experienced in earthquakes. A study by Gatto and Uang [25] compared the different testing procedures with the same specimens, they found that the results indicate that loading sequence has a significant influence on the shear wall with regards to the overall performance and just the shear capacity. Protocols with a large number of cycles (SPD) tended to produce nail fatigue fractures, which were not nearly as prevalent in protocols with lower numbers of cycles (CUREE) yet the initial stiffness of the specimens was relatively unaffected by the loading protocol used.

As such, different protocol was developed through the CUREE-Caltech wood-frame project [24]. In the formulation of this protocol, the number of cycles are fewer than some other methods and are more consistent with what is expected in real California design earthquakes. Furthermore, the potential for cumulative damage in the wood frame has been considered. This protocol, shown in Figure 1, uses an estimated target displacement obtained from a monotonic test to determine the amplitudes of the cyclic loading. From the monotonic loading test, the load at $80 \%$ of peak load on the descending curve (degradation) defines a displacement, $60 \%$ of which is assumed to be the drift that corresponds to the peak load and is the reference displacement for the cyclic loading protocol. This loading protocol has been successfully used by researchers studying light-frame construction such as the work by Bersofsky [19] and McMullin and Merrick [12].

The necessary number of tests will depend on the desirable parameter variation. According to ASTM E 2126, a minimum of two tests are needed for each type of specimen configuration, and a third test will be needed if the first two tests do not agree (e.g., capacity) within $10 \%$. For statistical purposes, it is preferred to have at least three specimens tested. The cyclic loading test protocol will also require a static monotonic loading test carried out before the cyclic loading test in order to determine target load and displacement values to be used in the cyclic loading. This would mean that four specimens will be required for testing each type of wall configuration (three cyclic and one monotonic).

\section{Experimental Program}

The experimental testing program of this study constructed and tested five specimens total with and without joint finish to determine the effect of joint compound on the shear strength of the wall panel. Three parts encompass the testing program, 1) the specimen construction, 2) the testing protocol, and 3) the testing facility and data acquisition system. The following sections describe each in detail.

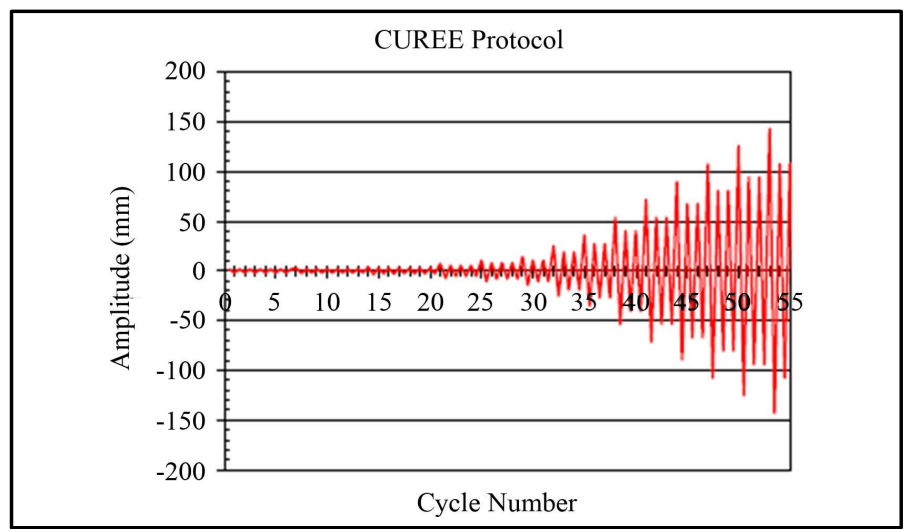

Figure 1. CUREE loading protocol showing cycle number versus target displacement. 


\subsection{Wall Specimen Construction}

Each specimen had overall dimensions of $2438 \mathrm{~mm}$ by $2438 \mathrm{~mm}$ ( $8 \mathrm{ft}$ by $8 \mathrm{ft}$ ). The wood stud framing was initially constructed on work benches using conventional $51 \mathrm{~mm}$ by $102 \mathrm{~mm}$ ( 2 in. $\times 4$ in.) nominal No. 2 sprucepine-fir studs. Mechanical properties for the fasteners are listed in Table 1 and joint compound properties are listed in Table 2. Each frame consisted of seven studs, one bottom plate, and a double top plate. The two $51 \mathrm{~mm}$ by $102 \mathrm{~mm}(2 \mathrm{in.} \times 4$ in.) double plates (Figure 2(d)) were attached to each other using $10 \mathrm{~d}$ common nails at $610 \mathrm{~mm}$ (24 in.) on center. The studs were connected to top and bottom plates using two $16 \mathrm{~d}$ common nails driven at an angle at each end. The wood-frame was then sheathed with two $13 \mathrm{~mm}(1 / 2$ in.) thick $1219 \mathrm{~mm}$ by $2438 \mathrm{~mm}(4 \mathrm{ft} \times 8 \mathrm{ft})$ drywall sheets on each side oriented horizontally to create a horizontal joint at mid-height of the panels.

The sheathing-to-framing connections for wood stud wall systems were chosen based on International Residential Code [26] specifications in order to build the specimens as close to conventional construction as possible. The drywall was attached to the framing using No. 8, $31.8 \mathrm{~mm}$ (1.25 in) coarse-threaded drywall screws at $101 \mathrm{~mm}$ (4 in.) o.c. for the perimeter and $203 \mathrm{~mm}$ (8 in.) o.c. for interior studs. Figures 2(a)-(c) show the construction of the specimens and the finishing of the joints. Figure 2(e) shows a finished specimen for testing. The finish material consisted of CTS Cement's Rapid Set OnePass joint compound and UGL 222 joint compound. The former was applied to the drywall by a CTS representative, while the latter was applied by a professional drywall installer. The applied areas were sanded after the joint compound had sufficiently dried (Figure 2(c)).

The process to construct the specimens followed traditional methods for fabricating wall panels as well as the application of the drywall followed traditional practices. This process is as follows for the wall construction and joint finishing [7] [15]:

1) Top and bottom plates are cut to length and in the case of the top plate; the two boards were nailed together.

2) Studs are cut to length, spaced per requirements, and then nailed to the top and bottom plates.

3) Drywall is attached to studs by screws on each face of sheathing.

4) The first coat of joint compound consists of a fiberglass reinforcing tape embedded in joint compound and centered over the seam.

5) Once the first coat is dry and lightly sanded, a second coat fills the remainder of the beveled depression between drywall panels.

6) The third coat is applied after the second coat is dry and sanded.

7) A final sanding is conducted to smooth any remaining roughness on the surface once thoroughly dried.

Overall, five specimens were tested, two with the Rapid Set OnePass and three with the UGL joint compound.

Table 1. Fastener properties.

\begin{tabular}{cccc}
\hline & Length mm (in.) & Diameter mm (in.) & Threads/Inch \\
\hline 10 d common nail & $76.2(3)$ & $3.7(0.148)$ & N/A \\
16 d common nail & $88.9(3.5)$ & $4.1(0.162)$ & 8 \\
No. 8 drywall screws & $31.8(1.25)$ & $4.1-4.6(0.163-0.180)$ & 8 \\
\hline
\end{tabular}

Table 2. Joint compound properties.

\begin{tabular}{|cccc}
\hline \multirow{2}{*}{ Joint compound type } & \multicolumn{2}{c}{ Compressive strength MPa (psi) } & Mix \\
\cline { 2 - 3 } & At 24 hours & At 28 days & 40\% (weight) water and 60\% OnePass powder \\
\hline CTS cement's rapid set OnePass & $11.72(1700)$ & $18.61(2700)$ & Pre-mixed \\
UGL 222 & N/A & $2.07(300)^{1}$ &
\end{tabular}

${ }^{1}$ Note: UGL 222 compressive strength was not tested or available from the manufacturer. The listed strength is from a competitor (SHEETROCK MH Brand Setting-Type Joint Compound) with a similar mix. 


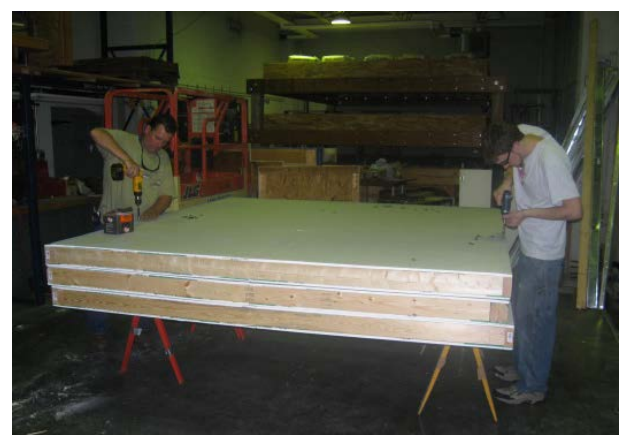

(a)

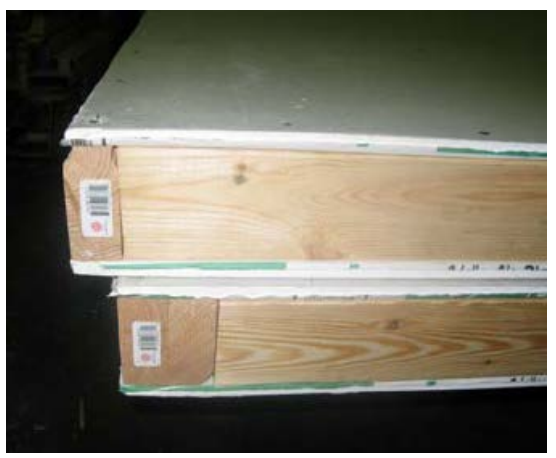

(d)

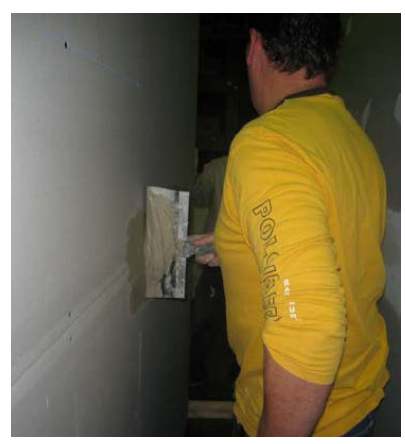

(b)

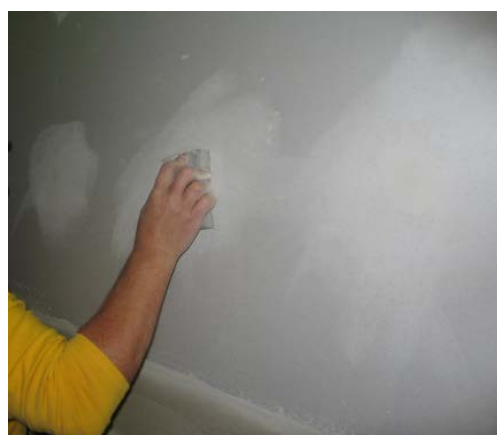

(c)

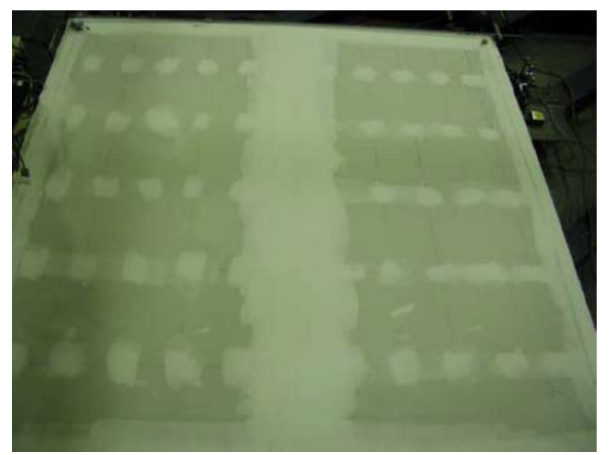

(e)

Figure 2. Construction and specimen details. (a) Attachment of sheathing; (b) Application of joint compound; (c) Finishing of joint compound; (d) Top and bottom plate; (e) Finished specimen.

Because Rapid Set OnePass joint compound is normally applied in one coat, it was of interest to evaluate the performance of a wall specimen with one coat after 24 hours of cure time (RPDST24HR1C) and another specimen with one coat after seven days of curing (RPDST7D1C). For the UGL compound, although it is normally applied in two coats, for comparison purposes, it was decided to evaluate the performance of three specimens as follows: one specimen finished with one coat and cured for 24 hours (UGL24HR1C), one specimen finished with one coat but cured for seven days (UGL7D1C), and finally one specimen finished with two coats and cured for seven days (UGL7D2C).

\subsection{Testing Protocol}

The testing protocol for this study followed that suggested in AETM E72, with the exception of the CUREE protocol, a slight variation in the test setup (different from ASTM E 2126). Instead of a Sequential Phased Displacement (SPD) Loading Procedure that is recommended in ASTM E 2126, the more recently developed CUREE Caltech Loading Protocol [24] was used as discussed previously. The displacement amplitudes applied (listed in Table 3) for racking tests were obtained from the results of the monotonic test on unfinished woodframe specimen from the previous study [27]. Additionally, a fewer number of specimens than that recommended in E 2126 were used. The displacement-controlled amplitudes of the displacement peaks for each cycle are shown in Figure 1. These points were controlled by the reference displacement $\Delta$, which was estimated from the monotonic load test [27], where the displacement $\Delta_{\mathrm{m}}$ corresponding to $80 \%$ maximum load strength, or $0.8 \mathrm{Fu}$. Then $60 \%$ of $\Delta_{\mathrm{m}}$ was used as this reference displacement $\Delta$.

\subsection{Testing Facility Description}

To conduct specimen testing of walls under cyclic loading, a horizontal testing frame (shown in Figure 3) located at the time in the Penn State's Agricultural and Biological Engineering (ABE) laboratory was used. The test frame lies horizontally on the laboratory floor such that a wall specimen would be placed flat on the support frame. The flat floor supported the structural steel frame which was fabricated from wide-flange steel beams 


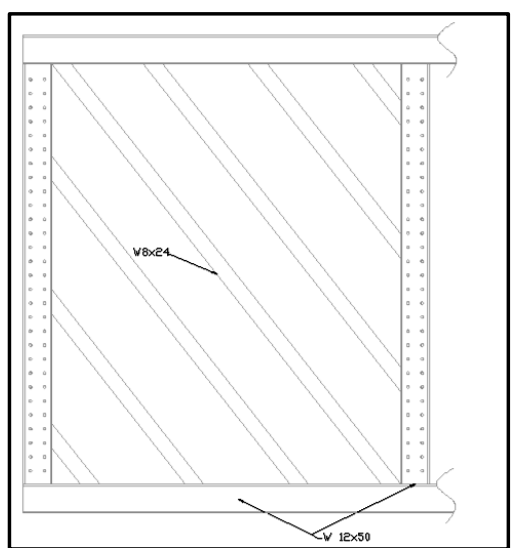

(a)

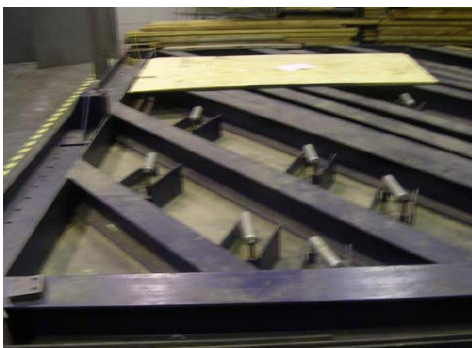

(c)

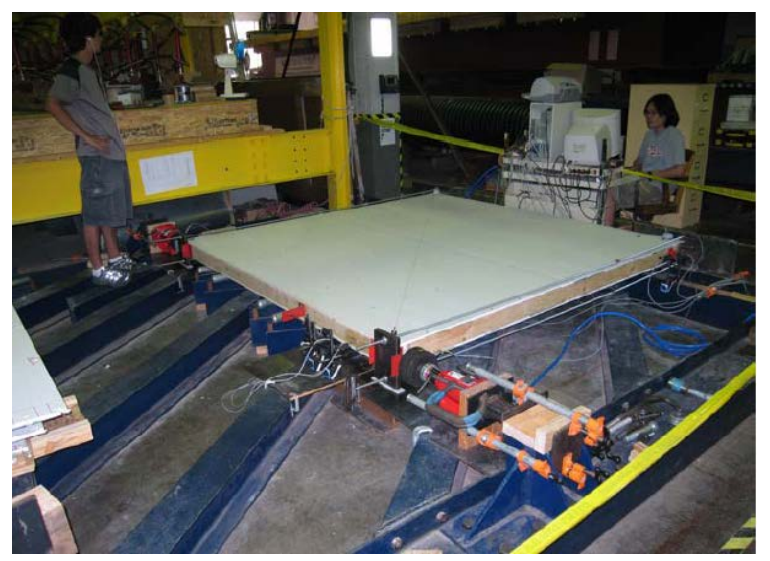

(b)

Figure 3. Facility layout and details. (a) Testing machine schematic layout; (b) Testing frame with specimen installed; (c) Roller support; (d) Actuator jack with load cell; (e) End condition for tie rods.

framed together using $25.4 \mathrm{~mm}$ ( 1 in) diameter bolts to form a rectangular frame with multiple diagonal members (Figure 3(a)). The W $12 \times 50$ beams on the perimeter were laid with their webs parallel to the floor, while the W $8 \times 24$ diagonal beams were laid with one flange on the floor. The specimen actually slides over rollers (Figure 3(c)). The load was applied to the specimen using a pair of 178-kN capacity bottleneck jacks (ATD737120-Ton Air Hydraulic Bottle).

Each loading jack had a stroke capacity of $89 \mathrm{~mm}$ (3.5 in) and was equipped with a load cell to measure the applied load to the wall specimen (Figure 3(d)). Tie-rods were used as pairs on either side of the specimen. The bottom of the wall specimen was attached to the support steel plates, which also provided the support for tierods (Figure 3(e)).

The parameters of interest that were measured during the tests included: the load exerted by the jack and specimen displacements at several points. A total of eight channels of data acquisition were employed. Loads were determined through the attached load cell while horizontal and vertical displacements were measured using a series of potentiometers. The schematic representation of the Data Acquisition Points can be seen in Figure 4. Horizontal displacements (lateral drift) were at the top of the wall, vertical displacement (uplift movement) were at tie-rod locations, slip of the wall was at the base, and wall diagonal length change (shear deformation of the wall panel) was across the specimen (shown in Figures 5(a)-(c)). Potentiometers had a movement range up to 203 $\mathrm{mm}$ (8 in).

\section{Test Results}

The objective of this study was to evaluate the performance of the tested specimens under an in-plane cyclic racking load protocol to determine if Rapid Set OnePass joint compound could provide higher shear capacity to light-frame walls compared to conventional non-cement based compounds. For each tested specimen, load-displacement plots were developed using the load data recorded by load cells and the displacements recorded by potentiometers. Hysteresis curves were then plotted for a selective number of primary cycles. The envelope curve generated by connecting peak points of primary cycles was also plotted. 
Table 3. Displacement control cyclic loading protocol.

\begin{tabular}{|c|c|c|c|c|c|}
\hline CYCLE & CYCLE TYPE $^{1}$ & \multicolumn{2}{|c|}{ MAGNITUDE $^{2}$} & DRIFT RATIO $(\%)^{3}$ & DEFLECTION AT TOP OF THE WALL (in.) \\
\hline $1,2,3,4,5,6$ & Initiation & 0.05 & $\Delta$ & 0.057 & 0.05 \\
\hline 7 & Primary & 0.075 & $\Delta$ & 0.086 & 0.08 \\
\hline $8,9,10,11,12,13$ & Trailing & 0.056 & $\Delta$ & 0.064 & 0.06 \\
\hline 14 & Primary & 0.1 & $\Delta$ & 0.114 & 0.11 \\
\hline $15,16,17,18,19,20$ & Trailing & 0.075 & $\Delta$ & 0.086 & 0.08 \\
\hline 21 & Primary & 0.2 & $\Delta$ & 0.228 & 0.21 \\
\hline $22,23,24$ & Trailing & 0.15 & $\Delta$ & 0.171 & 0.16 \\
\hline 25 & Primary & 0.3 & $\Delta$ & 0.342 & 0.32 \\
\hline $26,27,28$ & Trailing & 0.225 & $\Delta$ & 0.257 & 0.24 \\
\hline 29 & Primary & 0.4 & $\Delta$ & 0.456 & 0.42 \\
\hline 30,31 & Trailing & 0.3 & $\Delta$ & 0.342 & 0.32 \\
\hline 32 & Primary & 0.7 & $\Delta$ & 0.798 & 0.74 \\
\hline 33,34 & Trailing & 0.525 & $\Delta$ & 0.599 & 0.55 \\
\hline 35 & Primary & 1 & $\Delta$ & 1.140 & 1.05 \\
\hline 36,37 & Trailing & 0.75 & $\Delta$ & 0.855 & 0.79 \\
\hline 38 & Primary & 1.5 & $\Delta$ & 1.710 & 1.58 \\
\hline 39,40 & Trailing & 1.125 & $\Delta$ & 1.283 & 1.18 \\
\hline 41 & Primary & 2 & $\Delta$ & 2.280 & 2.10 \\
\hline 42,43 & Trailing & 1.5 & $\Delta$ & 1.710 & 1.58 \\
\hline 44 & Primary & 2.5 & $\Delta$ & 2.850 & 2.63 \\
\hline 45,46 & Trailing & 1.875 & $\Delta$ & 2.138 & 1.97 \\
\hline 47 & Primary & 3 & $\Delta$ & 3.420 & 3.15 \\
\hline 48,49 & Trailing & 2.25 & $\Delta$ & 2.565 & 2.36 \\
\hline 50 & Primary & 3.5 & $\Delta$ & 3.990 & 3.68 \\
\hline 51,52 & Trailing & 2.625 & $\Delta$ & 2.993 & 2.76 \\
\hline 53 & Primary & 4 & $\Delta$ & 4.560 & 4.20 \\
\hline 54,55 & Trailing & 3 & $\Delta$ & 3.420 & 3.15 \\
\hline 56 & Primary & 4 & $\Delta$ & 4.560 & 4.20 \\
\hline
\end{tabular}

${ }^{1}$ After each primary cycle, there are two trailing cycles with amplitudes $75 \%$ of the primary cycle amplitude; ${ }^{2} \Delta=60 \% \Delta \mathrm{m}$, where $\Delta \mathrm{m}$ is the displacement corresponding to $80 \%$ of maximum monotonic load; ${ }^{3}$ The drift ratio is the ratio of deflection at top of the wall divided by the height of the wall. 


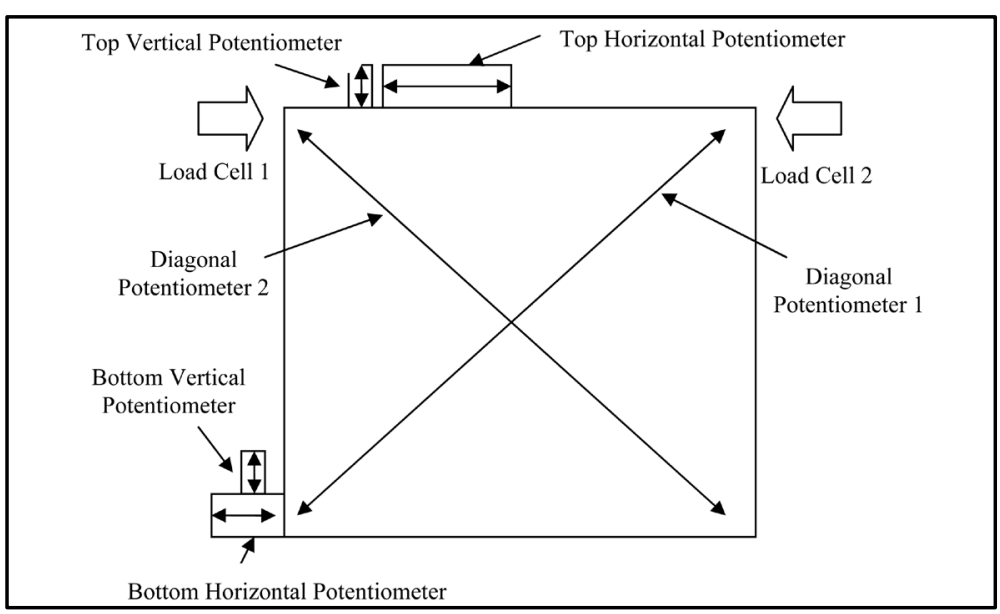

Figure 4. Location of data acquisition points per specimen.

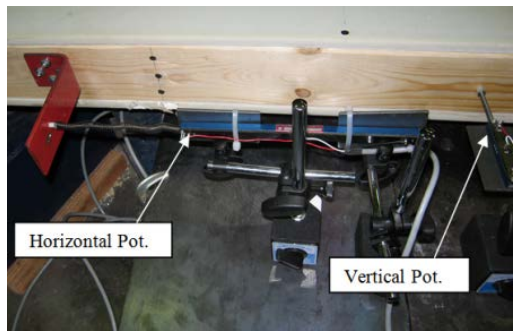

(a)

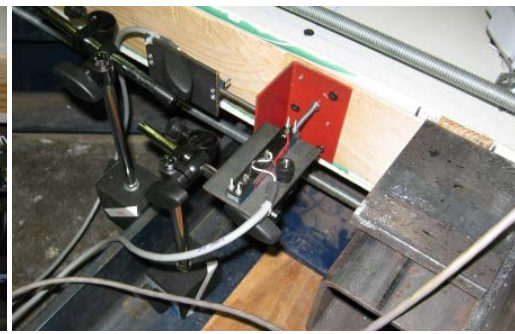

(b)

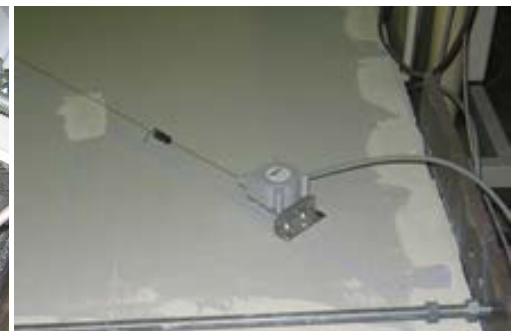

(c)

Figure 5. Potentiometer details. (a) Top of Specimen; (b) Bottom of specimen; (c) Across diagonal of specimen.

\subsection{Results from UGL Specimens}

Figures 6(a)-(c) shows a typical UGL specimen after testing with a crack through the entire horizontal drywall joint as well as details of the failure modes. Such modes were similar for all three UGL specimens. As the figures show, the UGL joint compound has cracked at the horizontal joint allowing the two drywall sheets slide pass each other at the joint. The hysteresis plots show the shear in the panel resulted in failure of the drywall joint through cracking of the joint compound and tearing the mesh tape. On the other hand, there was no relative movement of top or bottom plates with respect to the drywall. This means that drywall screws at top and bottom plates and stud screws closer to top and bottom plates did not make enlarged holes in the drywall since the horizontal joint compound was weaker in resisting the shear. Figures 7(a)-(c) show the load-displacement hysteresis curves for the three UGL specimens. The monotonic load-displacement curve for an unfinished specimen tested previously [27] is also plotted to show the effect of finishing joint compound.

Observing the failure mechanisms upon closer examination, their characteristics can be compared to previous studies and known behavior. The UGL compound had certain resistance to shear behavior but due to the brittle nature of gypsum (the main component in the compound) it can be expected and was observed that upon reaching cracking load the joint crack and the capacity was immediately lost. The joint movement converted the action of a joint system into two side by side systems of drywall thus the lack of screw tear out.

The plotted test results show that the peak shear strength based on the envelope curve is approximately 14.23 kN (3200 lb), $16.24 \mathrm{kN}$ (3650 lb), and $14.90 \mathrm{kN}$ (3350 lb), respectively, for UGL24HR1C, UGL7D1C, UGL7D2C specimens. The monotonic test peak for an unfinished specimen is approximately $12.45 \mathrm{kN}$ (2800 b). These results show that longer cure times can increase the strength of UGL joint compounds and that using two coats of compound may not necessarily result in an increased shear capacity over one coat. However, since these results are based on only one specimen of each configuration, obviously one cannot draw definitive conclusions which should be based in the future on a statistically sound number of specimens. Nonetheless, the results definitely show that significant strength and reserve capacity is brought about by the type and finish of the compound. 


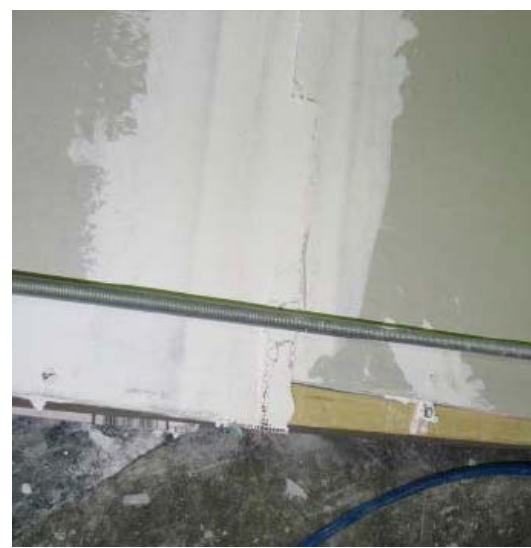

(a)

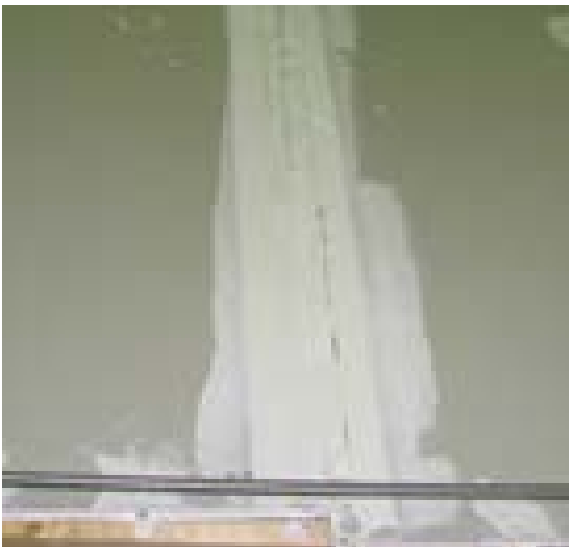

(c)

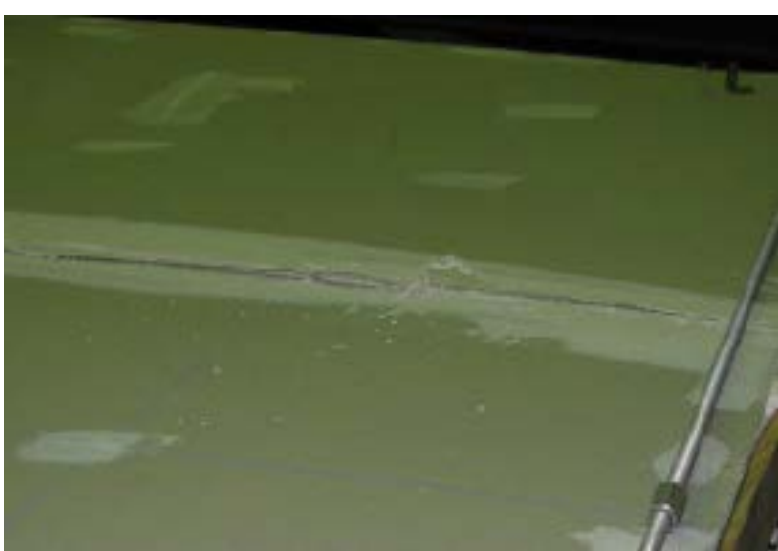

(b)

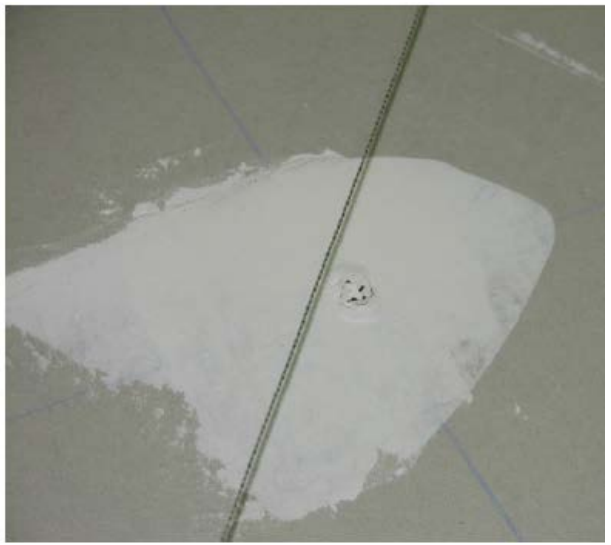

(d)

Figure 6. UGL specimen failure modes. (a) UGL edge tearout; (b) Relative movement of drywall; (c) UGL horizontal joint crack; (d) UGL screw attachment.

Comparison of the average peak value of the three tests, which is $15.12 \mathrm{kN}$ (3400 lb), with the monotonic peak value of the unfinished specimen $12.45 \mathrm{kN}(2800 \mathrm{lb})$ shows a ratio of 1.21, or $21 \%$ increase in shear capacity due to the finishing of the joint with UGL. Although specimen UGL7D2C showed a smaller shear capacity compared to specimen UGL7D1C, nevertheless, it is expected that a thicker coat will result in higher capacity. The peak value of the envelope curve can be considered as the ultimate shear strength for a given specimen. Using a factor of safety of 3.0, which is normally used for light-frame wall systems, an estimate for the allowable shear value can be found. On the basis of the average peak value, the allowable shear value for the UGL specimens was approximately $5.03 \mathrm{kN}(1130 \mathrm{lb})$.

\subsection{Results from Rapid Set OnePass Specimens}

The same type of test results were developed for the two specimens finished using Rapid Set OnePass joint compound. Figures 8(a)-(c) show one of the Rapid Set OnePass specimens upon completion of the test including several details on the failure mode. The failure modes for all specimens (two) were practically the same. The figure shows that the Rapid Set OnePass joint compound did not crack at the drywall joint and that there was no sliding of the two drywall sheets against one another. Because the joint compound did not crack at the horizontal drywall joint, the screws pushed through the drywall to accommodate the frame deformation. Figure 8 clearly shows that unlike the UGL specimens, there is no relative movement between drywall sheets at the joint when the loading jack in fully extended. Figures 9(a) and (b) show the load-displacement hysteresis curve plots for the two Rapid Set OnePass specimens along with the monotonic curve for the unfinished specimen.

Upon closer examination of the failure mechanisms, their characteristics can be compared more closely to mechanisms observed using fiber reinforcing for repair work. The Rapid Set OnePass compound had crack re- 


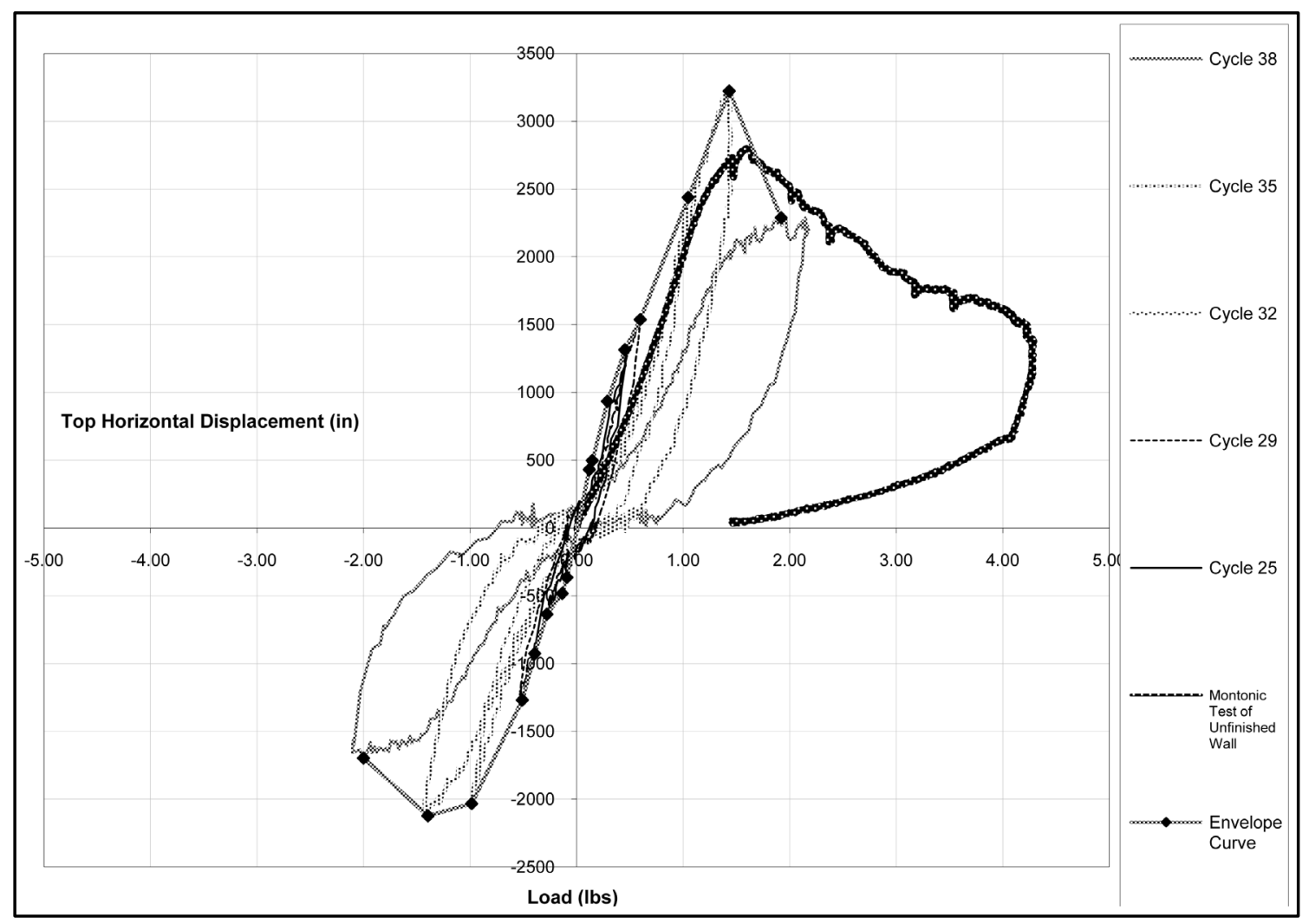

(a)

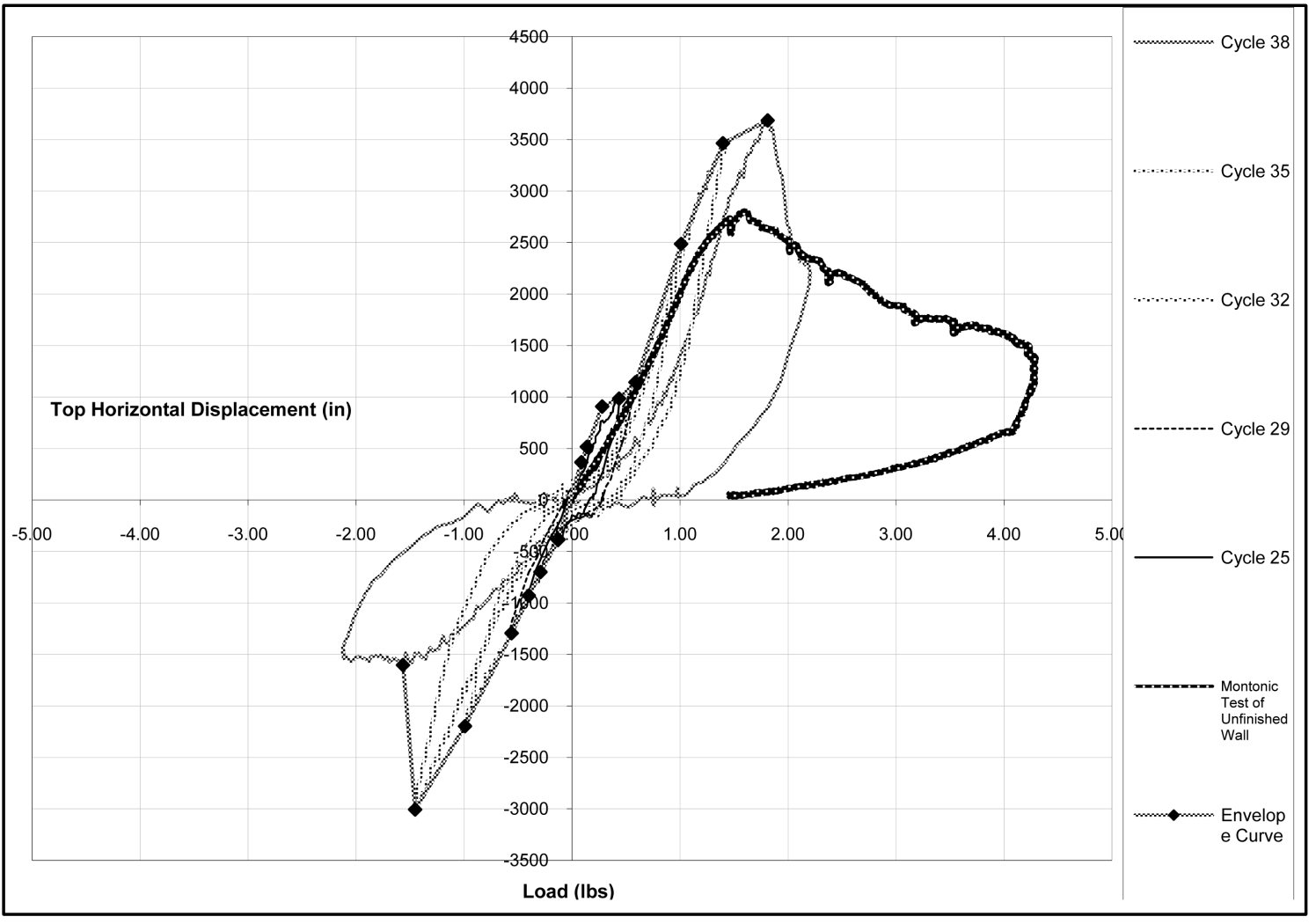

(b) 


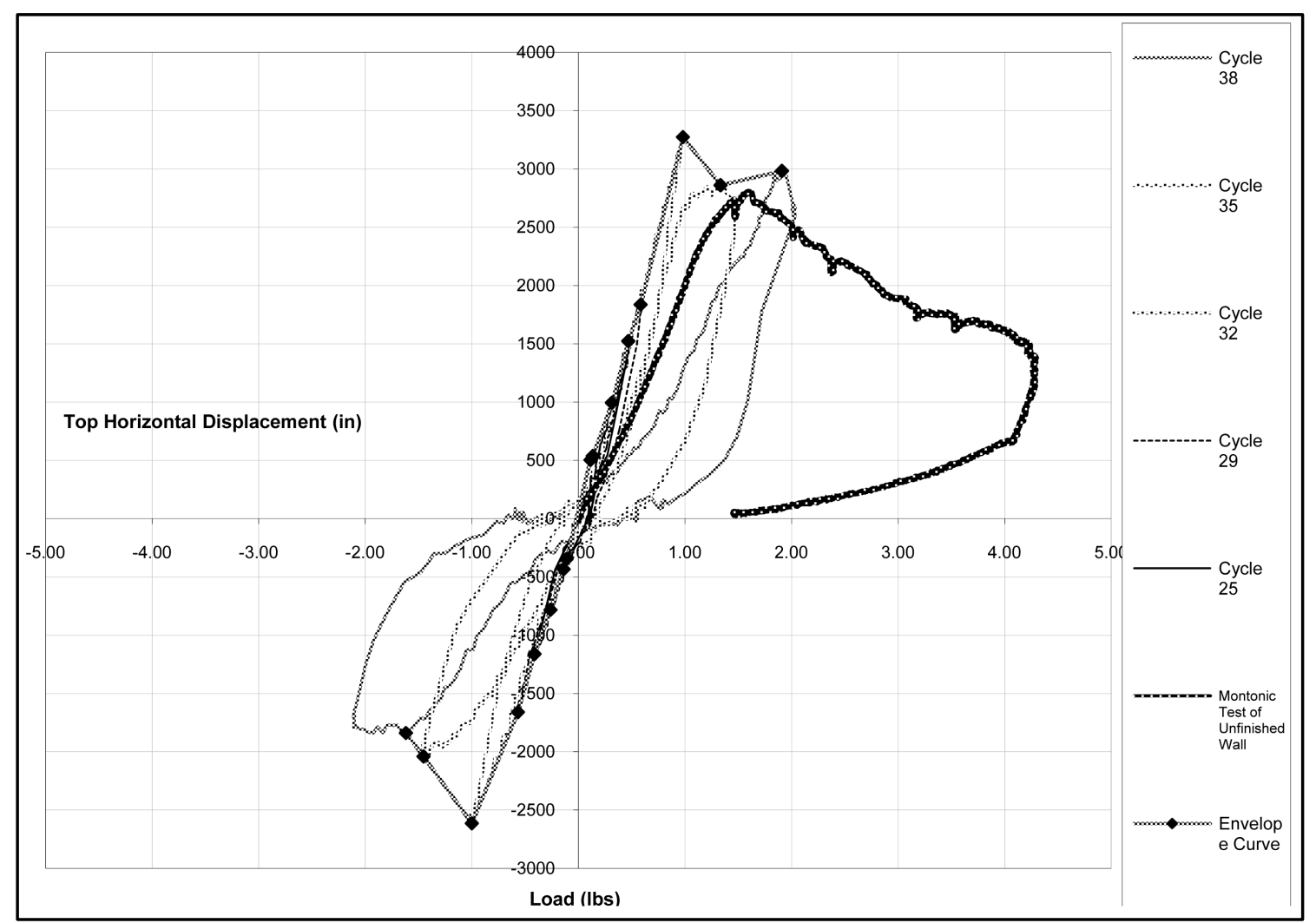

(c)

Figure 7. UGL specimens’ load-displacement hysteresis curves. (a) Specimen UGL24HR1C; (b) Specimen UGL7D1C; (c) Specimen UGL7D2C.

sistance due to the following: the shear behavior of the material is naturally stronger than gypsum, the material has higher adhesive properties for material bonding, and when combined with the fiber tape acts like a fiber reinforced joint similar to concrete repair. As a result of this increase, the bearing around the screws attaching the drywalls exceeded capacity and tore out due to the relative stiffness of the drywall layer to study layer.

The test results show that the envelope peak value for shear strength is approximately $22.24 \mathrm{kN}$ (5000 lb) for both specimens. This shows that for the Rapid Set OnePass joint compound, a longer (more than 24 hours) cure time will not necessarily increase the system capacity. Compared to the monotonic test on unfinished specimen, a peak strength ratio of 1.78 was observed. This meant there was a $78 \%$ increase in shear capacity due to finishing the joint with Rapid Set OnePass joint compound. The allowable shear value for these specimens was approximately $7.38 \mathrm{kN}(1660 \mathrm{lb})$.

\subsection{Discussion and Comparison of UGL and OnePass Joint Compound Test Results}

Next, in the interest to understand how the cement based joint compound performed against the more traditional type, comparisons across the different performance metrics were conducted. The first aspect to compare the UGL and OnePass specimens against is their failure modes. The images in Figures 6 and 8, in particular, show the difference in failure modes for the joint compounds. Close inspection of the OnePass specimen after the test showed that the OnePass joint compound had bonded to the drywall paper through the mesh joint tape, and that the tape could not be peeled off after the test. For the UGL compound, however, the tape could be peeled off, exposing the drywall paper. This is attributed to the adhesive cement component found in the OnePass material that provided a superior bond over what the gypsum based material contained. The second and more important comparison, however, is the peak load. As described earlier, the test results show that the average shear strength of the OnePass specimens is $22.24 \mathrm{kN}$ (5000 lb), while that for UGL specimens is $15.12 \mathrm{kN}$ (3400 lb). This shows that the OnePass specimens had on average 47\% higher shear strength compared to the UGL specimens. 


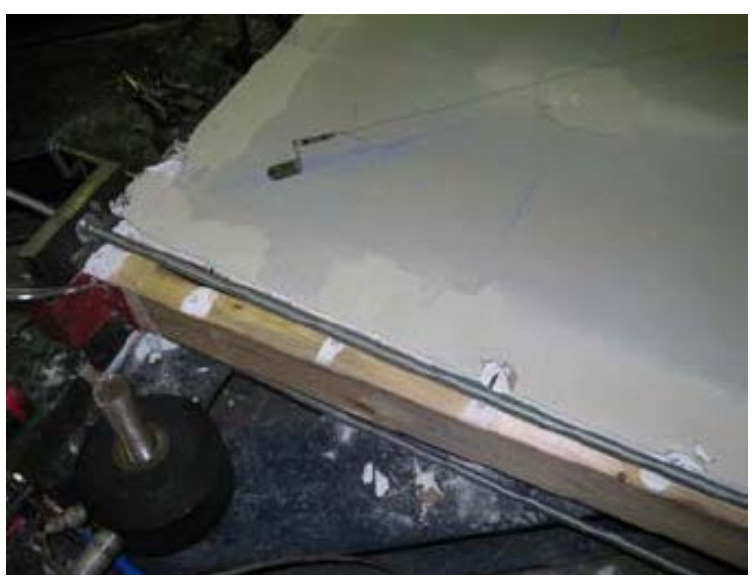

(a)

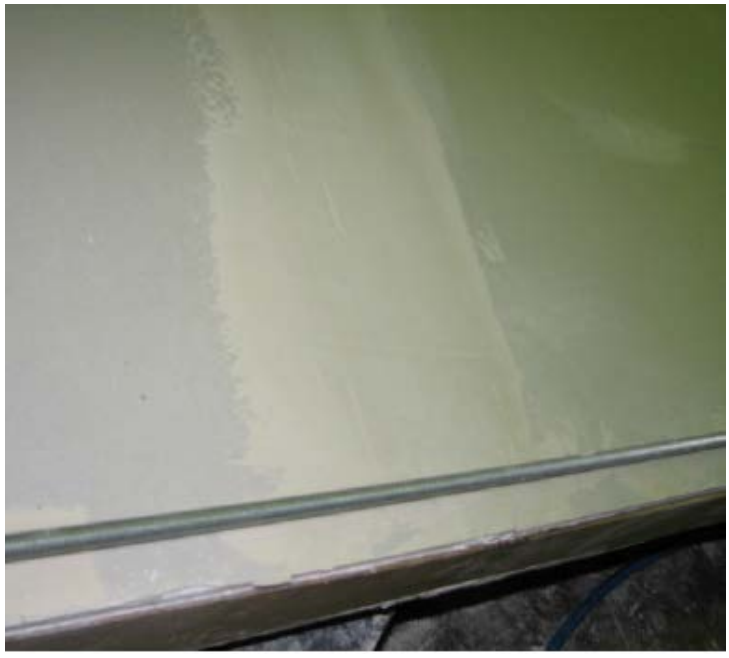

(c)

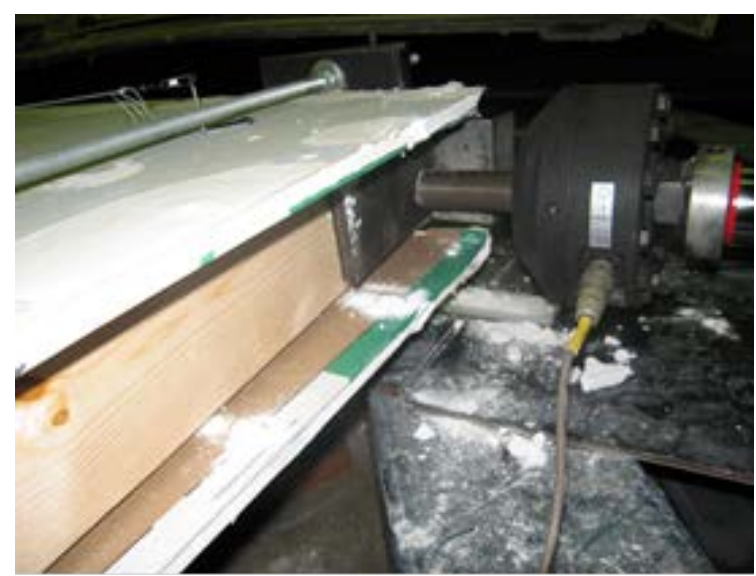

(b)

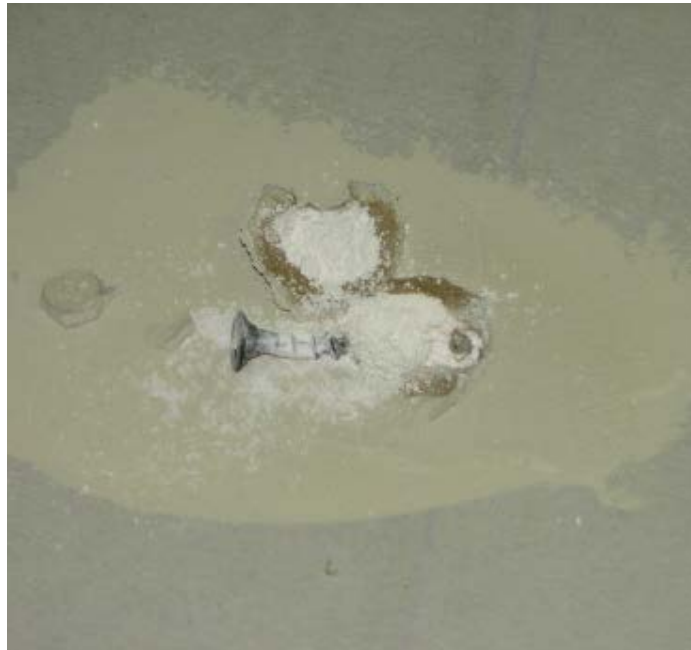

(d)

Figure 8. Rapid set OnePass specimen failure modes. (a) Rapid set edge tearout; (b) Detachment of drywall at peak load; (c) Rapid set horizontal joint with no crack; (d) Rapid set screw attachment.

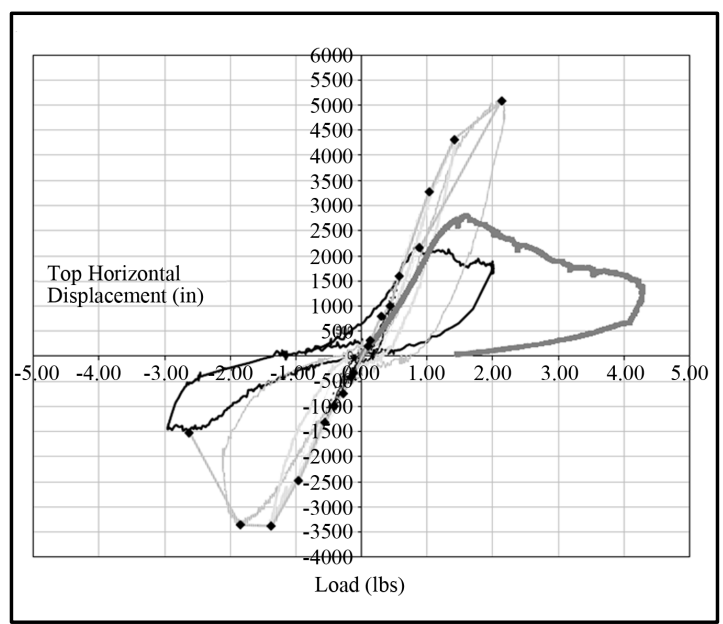

(a)

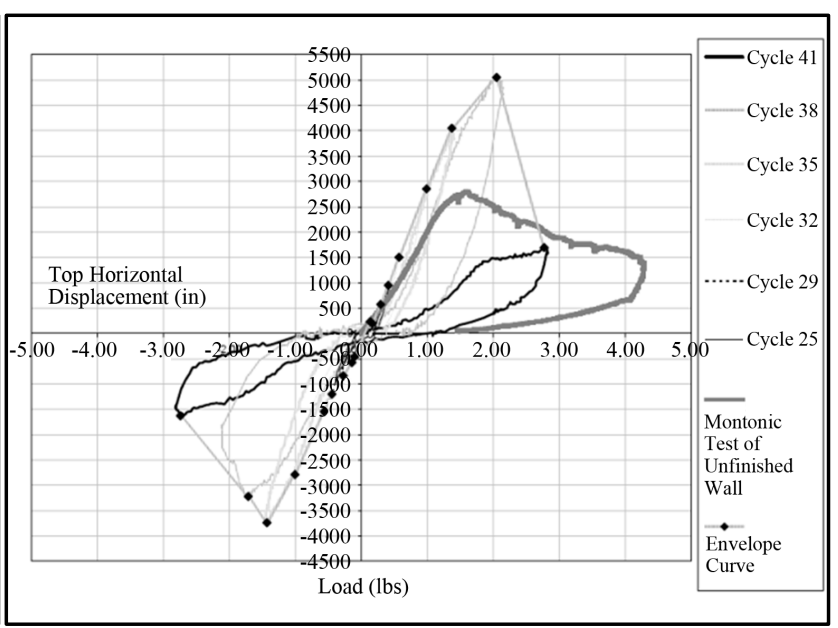

(b)

Figure 9. Rapid set OnePass specimens load-displacement hysteresis curves. (a) Specimen RPDST24HR1C; (b) Specimen RPDST7D1C. 
Based on observations during testing, it is believed that higher shear strength is achieved predominately through the strengthening of the joint between the two drywall sheets. Instead of two sheets moving independently with only friction between them, both joint compounds provide resistance to allow for single panel action. Significant increase between UGL and OnePass can be attributed to their cement based mix and how it interacted with the surface and joint tape.

To compare all five specimens, the envelop curves are plotted against one another in Figure 10. The plotted test results clearly show the difference in peak points of shear resistance. Once past the peak point, the capacity drops and that is where the tests were terminated. In comparing the specimens to other tests that have been conducted there are similar interesting trends (see Table 4). In relation to Memari et al. [27], the OnePass specimens had $88 \%$ higher shear capacity as compared to an unfinished joint. Comparing the OnePass specimen to OSB on wood studs [7], the OnePass had 55\% of the capacity that OSB had, which is quite specific. The same comparison with the unfinished specimen shows $29 \%$ of the OSB sheathed capacity and with the UGL finished specimen shows $40 \%$ of the OSB capacity. To compare OnePass wood studs with metal studs [5] [27], it is ob-

Table 4. Capacities of specimens and other configurations.

\begin{tabular}{cccc}
\hline Stud Type & Sheathing Type & Joint Type & Shear Capacity kN \\
\hline Wood $^{1}$ & GWB & Unfinished & 11.79 \\
Wood & GWB & UGL & 15.12 \\
Wood & GWB & OnePass & 22.24 \\
Wood $^{3}$ & OSB & N/A & 40.10 \\
Steel $^{1}$ & GWB & Unfinished & 6.23 \\
Steel $^{1}$ & GWB & UGL & 8.67 \\
Steel $^{2}$ & OSB & N/A & 17.5 \\
\hline
\end{tabular}

${ }^{1}$ These results are based on the earlier study by Memari et al. [20]; ${ }^{2}$ Chen et al. [5]; ${ }^{3}$ Uang and Gatto [7].

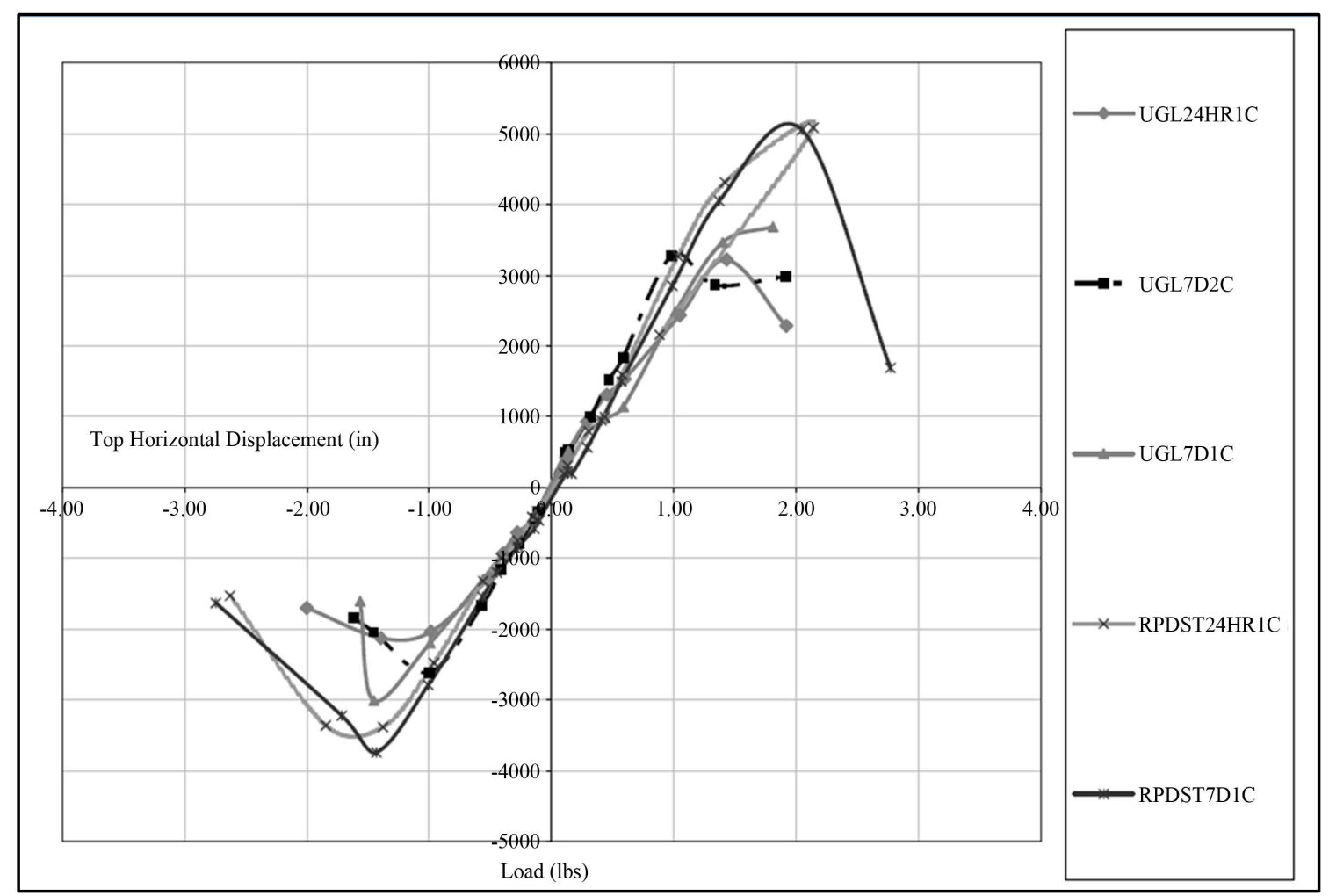

Figure 10. Comparison of the envelope curves for all five specimens. 
served that OnePass has 27\% higher capacity than steel studs with OSB and has 253\% more capacity than steel studs with unfinished joints. Overall it is clear that wood studs have higher shear resistance with drywall and with finished joints. Also the element of cementitious reinforced joint compound provides an increase in shear capacity to the point where it is becoming comparable to wood studs with OSB.

\section{Conclusions and Recommendations}

The findings of this study determined whether the type of drywall joint compound would influence the shear strength of wood-frame stud walls sheathed with drywall. In this study, a total of five $2438 \mathrm{~mm}$ by $2438 \mathrm{~mm}$ (8 $\mathrm{ft}$ by $8 \mathrm{ft}$ ) specimens were tested under in-plane cyclic racking loading following the CUREE loading protocol for light-frame wall systems. Three specimens were finished using UGL joint compound with different combinations on the number of finish coats and curing period. The other two specimens were finished using Rapid Set OnePass joint compound with two different curing periods. The following conclusions are drawn from the results of this study:

- Compared to the monotonic test on the unfinished specimen, there is a $21 \%$ increase in shear capacity due to finishing the joint with UGL compound.

- Compared to the monotonic test on the unfinished specimen, there is a 78\% increase in shear capacity due to finishing the joint with Rapid Set OnePass joint compound.

- The capacities represented by envelope curves for cyclic tests show that the OnePass specimens had on the average $47 \%$ higher shear strengths compared to the UGL specimens.

- OnePass joint compound had bonded to the drywall paper through the mesh joint tape, and that the tape could not be peeled off as compared to the UGL compound that was bonded to mesh joint tape yet the tape could be peeled off, exposing the drywall paper. This indicates a stronger joint with the OnePass.

Based on the limited number of specimens tested, the results show that the use of CTS Cement Rapid Set OnePass joint compound on drywall joints as in the specimens tested will result in significantly higher shear capacity of the wall as compared to similar specimens finished with conventional non-cement based joint compound. With the addition of CTS Cement Rapid Set OnePass the walls became much closer to the wood studs sheathed with OSB. This is important in that the partitions could play a larger role in lateral load capabilities in residential houses if cement based compounds are used. The UGL compound applied onto horizontal drywall joints developed a crack over the entire length of the joint due to relative sliding of the two drywall sheets, while the specimens finished with Rapid Set OnePass compound did not develop such cracking. The failure modes for the specimens finished with the two different types of compound were different.

These results are particularly important in areas of high seismic activity where interior stud walls in residential construction effectively take part in seismic resistance even though plywood shear walls are normally used on exterior walls. This study shows that the type of joint compound finish material can make a difference in the level of overstrength and reserve capacity that interior drywalls could provide to the overall lateral force resistance. It is recommended that a follow-up comprehensive study be carried out and include the following:

- Evaluate the cyclic racking test performance of $2438 \mathrm{~mm}$ by $2438 \mathrm{~mm}$ ( $8 \mathrm{ft}$ by $8 \mathrm{ft}$ ) specimens finished using several different cement-based joint compounds and compare to specimens.

- Evaluate the effect of using cement-based joint compound on both wood stud and steel stud specimens.

- Evaluate the performance of finished specimens with openings; it is anticipated that cement-based compound will show better resistance at corner areas where drywall cracks usually start.

- Evaluate the effect of cement-based joint compound on the ductility response.

\section{Acknowledgements}

The financial support of the CTS Cement Manufacturing Company for this study is gratefully acknowledged. The contribution of the following individuals as also acknowledged: William Splain, Matt Sambol, Andrew Adams, Thomas Kuczynski, and Joseph Standley. The opinions expressed here are those of the authors only and do not necessarily reflect those of the sponsor.

\section{References}

[1] Kircher, C.A. (2003) It Makes Dollars and Sense to Improve Nonstructural System Performance. Proceedings of ATC 29-2 Seminar of Seismic Design, Performance and Retrofit of Nonstructural Components in Critical Facilities, New- 
port Beach, 109-120.

[2] Earthquake Engineering Research Institute (1990) Loma Prieta Earthquake Reconnaissance Report. Earthquake Spectra, 6, 43-48.

[3] Earthquake Engineering Research Institute (1995) Northridge Earthquake Reconnaissance Report. Earthquake Spectra, 2, 1-104.

[4] Serrette, R.L., Encalada, J., JuadinesM. and Nguyen, H. (1997) Static Racking Behavior of Plywood, OSB, Gypsum, and Fiberboard Walls with Metal Framing. Journal of Structural Engineering, 123, 1079-1086. http://dx.doi.org/10.1061/(ASCE)0733-9445(1997)123:8(1079)

[5] Chen, C.Y., Boudreault, F.A., Branston, A.E. and Rogers, C.A. (2006) Behavior of Light-Gage Steel-Framed Wood Structural Panel Shear Walls. Canadian Journal of Civil Engineering, 33, 573-587. http://dx.doi.org/10.1139/106-015

[6] Karacabeyli, E. and Ceccotti, A. (1999) Nailed Wood-Frame Shear Walls for Seismic Loads: Test Results and Design Considerations. Proceedings, Structural Engineering World Wide, Paper Reference T207-6, 1-9.

[7] Uang, C. and Gatto, K. (2003) Effects of Finish Materials and Dynamic Loading on the Cyclic Response of Woodframe Shearwalls. Journal of Structural Engineering, 129, 1394-1402. http://dx.doi.org/10.1061/(ASCE)0733-9445(2003)129:10(1394)

[8] Hart, G.C., Jain, A., Dumortier, A., Simsir, C. and Barnes, M.S. (2012) Start of Structural Damage in Stucco Walls. The Structural Design of Tall and Special Buildings, 21, 16-27. http://dx.doi.org/10.1002/tal.595

[9] Hart, G.C., Hortacsu, A., Simsir, C. and Jain, A. (2010) Performance of Drywall Shear Walls: UC Irvine and CSU San Jose Tests. The Structural Design of Tall and Special Buildings, 19, 309-345.

[10] Wolfe, R.W. (1983) Contribution of Gypsum Wallboard to Racking Resistance of Light-Frame Walls. Forest Products Laboratory Research Paper FPL439, US Department of Agriculture, Madison.

[11] Skaggs, T.D. and Rose, J.D. (1998) Cyclic Load Testing of Wood Structural Panel Shear Walls. Proceedings, Structural Engineering World Wide, 1-10.

[12] McMullin, K.M. and Merrick, D. (2002) Seismic Performance of Gypsum Walls: Experimental Test Program, CUREE-Caltech Wood-Frame Project. Consortium of Universities for Research in Earthquake Engineering, Richmond.

[13] Arnold, A.E., Uang, C.M. and Filiatrault, A. (2003) Cyclic Behavior and Repair of Stucco and Gypsum Woodframe Walls: Phase I. Consortium of Universities for Research in Earthquake Engineering, Richmond.

[14] Lee, T., Kato, M., Matsumiya, T., Suita, K.N. and Nakashima, M. (2007) Seismic Performance Evaluation of NonStructural Components: Drywall Partitions. Earthquake Engineering \& Structural Dynamics, 36, 367-382.

[15] van de Lindt, J.W. (2008) Experimental Investigation of the Effect of Multiple Earthquakes on Woodframe Structural Integrity. Practice Periodical on Structural Design and Construction, 13, 111-117. http://dx.doi.org/10.1061/(ASCE)1084-0680(2008)13:3(111)

[16] Zacher, E.G. and Gray, R.G.(1985) Dynamic Tests of Wood Framed Shear Walls. Proceedings of the SEAOC 57th Annual Convention, Structural Engineers Association of California, San Francisco, 41-61.

[17] NAHB (1997) Monotonic Test of Cold-Formed Steel Shear Walls with Openings. NAHB Research Center, Inc., The American Iron and Steel Institute, Washington DC.

[18] SEAOSC (1997) Standard Method of Cyclic Reverse Load Tests for Shear Resistance of Framed Walls for Buildings. Structural Engineers Association of Southern California, Whittier.

[19] Bersofsky, A.M. (2004) A Seismic Performance Evaluation of Gypsum Wallboard Partitions. M.S. Thesis, University of California, San Diego.

[20] Memari, A.M., Kasal, B., Manbeck, H.B. and Adams, A.R. (2009) Lateral Load Resistance Evaluation of Wood- and Steel-Stud Partition Shear Walls. Journal of Architectural Engineering, 15, 122-130. http://dx.doi.org/10.1061/(ASCE)1076-0431(2009)15:4(122)

[21] ASTM (1998) Standard Test Methods of Conduction Strength Tests of Panels for Building Construction. ASTM E72-98, West Conshohocken.

[22] ASTM (2000) Standard Practice for Static Load Test for Shear Resistance of Framed Walls for Buildings. ASTM E564-00, West Conshohocken.

[23] ASTM (2002) Standard Test Method for Cyclic (Reversed) Load Test for Shear Resistance of Walls for Buildings. ASTM E 2126-02a, West Conshohocken.

[24] Krawinkler, H., Parisi, F., Ibarra, L., Ayoub, A. and Medina, R. (2002) Development of a Testing Protocol for Wood Frame Structures. CUREE—Caltech Woodframe Project, Consortium of Universities for Research in Earthquake Engineering, Richmond. 
[25] Gatto, K. and Uang, C. (2003) Effects of Loading Protocol on the Cyclic Response of Woodframe Shearwalls. Journal of Structural Engineering, 129, 1384-1393. http://dx.doi.org/10.1061/(ASCE)0733-9445(2003)129:10(1384)

[26] International Code Council (2006) International Residential Code for One- and Two-Family Dwellings. International Code Council, Inc., Falls Church.

[27] Memari, A.M., Kasal, B., Adams, A.R. and Manbeck, H.B. (2008) Comparison of In-plane Lateral Load Resistance of Interior Steel Stud and Wood Stud Light-Frame Walls. Proceedings of the ASCE Structures Congress 2008, 24-26 April 2008, Vancouver, 1-10. 